\title{
The Application of Thematic Progression to the Text Analysis
}

\author{
Wei Zhang \\ Foreign Languages College, Beihua University, Jilin 132013, China
}

\begin{abstract}
Keywords: Thematic Progression; Text Analysis; Application.
\end{abstract}
\begin{abstract}
Since Danes (1974) firstly developed five patterns of Thematic Progression, many scholars at home and abroad (Fries, 1983; Bloor and Bloor, 1995; Xu, 1983\&1985; Huang Guowen, 1988; Hu Zhuanglin, 1994; Zhu Yongsheng, 1995) have made their own special efforts and contributions. Different scholars put forward different thematic progression patterns, although there are some overlapping parts of their proposals. In this paper, Zhu Yongsheng and Yan Shiqing's (2001) patterns will be employed to make an analysis of a randomly-chosen text to prove that thematic progression patterns are useful in the text analysis.
\end{abstract}

\section{Introduction}

Systemic functional linguistics takes a socio-linguistic perspective to language and argues that language is a hierarchical system of meaning potential and can perform miscellaneous functions. As to the functions of language, M. A. K. Halliday (1994) puts forward three metafunctions: ideational, interpersonal, and textual. The process of producing or creating a text is a process of actualizing the meaning potential. The textual metafunction refers to the fact that language has mechanisms to make any stretch of spoken or written discourse into a coherent and unified text (Halliday, 1994). Thematic structure reflects the common pattern of semantic origination of language in use. It is a subsystem to realize textual metafunction.

\section{Formation of Thematic Progression}

Thematic structure consists of the Theme and the Rheme, the categories of which were originally put forward by Mathesius, one of the most outstanding representatives of the Prague School. "The Theme is the starting point for the message; it is the ground from which the clause is taking off" (Halliday, 1994:38). It is also called Psychological Subject referring to "that which is the concern of the message" (Halliday, 1994:31), because it is what the speaker has in his mind to start with when producing a clause. "The Rheme is the remainder of the message, the part in which the Theme is developed (Halliday, 1994:37).” Theme can be subdivided into Unmarked Theme and Marked Theme. The Theme that is considered as being more usual and more common is referred to as Unmarked Theme and the more unusual and less common is named Marked Theme. Besides, the Theme can also be cut into Simple Theme and Multiple Theme. The latter may further embody the optional textual and / or interpersonal Theme and a compulsory experiential or topical Theme. The principle for identifying Theme is like this: Theme always contains one, and only one, experiential or topical Theme (Halliday, 1994:52). This means that the Theme of a clause ends with the first constituent that is either participant, circumstance or process.

Each clause has its own thematic structure. When the clause stands in isolation, its Theme and Rheme are fixed and are without any change. However, as far as the text is concerned, for most texts are composed of more than one clause structure, there are some connections and changes between the Theme in the previous clauses and the Theme in the subsequent clauses. The same connections and changes will also occur to the Rhemes and between the Theme and the Rheme. Such connections and changes are called thematic progression patterns (Zhu Yongsheng, 2001:102). With thematic progression, the whole text will develop gradually to form a whole meaningful text. Many linguists, both home and abroad, have studied and put forward various thought-provoking patterns of Thematic Progression and contributed their share to furthering such research. Since F. Danes (1974) firstly developed five patterns of Thematic Progression, many other scholars (Fries, 1983; Bloor and Bloor, 
1995; Xu, 1983\&1985; Huang Guowen, 1988; Hu Zhuanglin, 1994; Zhu Yongsheng, 1995) have made their own special efforts and contributions.

\section{Patterns of Thematic Progression}

According to Zhu Yongsheng and Yan Shiqing (2001:103-104), there are four basic patterns of thematic progression, namely:

1) Continuous Theme Pattern (the same Theme and different Rhemes)

$$
\begin{aligned}
& \mathrm{T} 1-\mathrm{R} 1 \\
& \downarrow \\
& \mathrm{T} 2(=\mathrm{T} 1)-\mathrm{R} 2 \\
& \cdot \\
& \cdot \\
& \cdot \\
& \mathrm{Tn}(=\mathrm{T} 1)-\mathrm{Rn}
\end{aligned}
$$

Example: The brain contains 10 billion nerve cells, making thousands of billions of connections with each other. It is the most powerful data processor we know.

2) Continuous Rheme Pattern (different Themes and the same Rheme)

$$
\begin{aligned}
& \text { T1-R1 } \\
& \text { T2-R2 (=R1) } \\
& \cdot \\
& \cdot \\
& \text { Tn } \\
& \text { Tn (=R1) }
\end{aligned}
$$

Example: England is a country; France is a country; Turkey is another country; Egypt, Italy and Poland are other countries.

3) The Extending Theme Pattern (the Rheme or a part of the Rheme in the previous sentence as the Theme in the subsequent sentences)

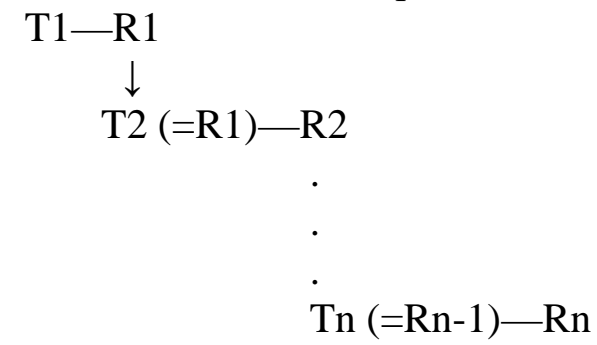

Example: Outside my window is a big lawn. In the middle of the lawn is a flower bed. This bed is full of daffodils.

4) The Interchanging Theme Pattern (the Theme in the previous sentence as the Rheme in the subsequent sentences)

$$
\begin{aligned}
& \stackrel{\mathrm{T} 1-\mathrm{R} 1}{\downarrow} \\
& \mathrm{T} 2-\mathrm{R} 2 \\
& \cdot \\
& \cdot \\
& \text { Tn }-\mathrm{Rn}(=\mathrm{Tn}-1)
\end{aligned}
$$

Example: The play was interesting, but I didn't enjoy it. A young man and a young woman troubled me. I turned around and looked at them, but they didn't pay any attention to me.

The patterns mentioned above are basic ones. However, many language materials show that different patterns of thematic progression will be used in certain text. 


\section{The Application of Thematic Progression to Text Analysis}

When a text is analyzed through thematic progression, the first step is to list all the Themes in sequence of the whole text. Then through patterns of thematic progression, the development of the whole text will be illustrated. To show this point, a text will be selected randomly to make an analysis. To be more scientific, the text is chosen at random from the last paragraph of Lesson Two in Integrated Skills of English, Book II as follows:

In 1863, the Football Association approved a game that outlawed carrying and kept the ball at men's feet. The game still had a long way to go, however, before it would be the football watched by millions around the world on television during the World Cup. Whole teams would rush back and forward on the field with the ball kept close at their feet; there were no passes or long kicks, and some of the rules used in those days were still nearer rugby than football. By the early 1870s, however, the fast, exciting, and open game of modern Association football was beginning to appear. The goal became standard, with a hard crossbar instead of a long piece of tape, and the goalkeeper was the only person permitted to use hands to play. In the process, football changed irrevocably from a gentleman's weekend exercise to the greatest spectator sport in the history of the human race.

After roughly reading the text, the first step is to list all the Themes in sequence. There are altogether 8 independent clauses in this text, and the 8 themes of this text are listed as follows

$\mathrm{T} 1$ in 1863

T2 the game

T3 whole teams

T4 there

T5 by the early 1870 s

T6 the goal

T7 the goalkeeper

T8 in the process

From T1 to T8, the topic of the whole text is clear. It is about the development of football game. In the beginning, middle and end part of the text, there are three Themes concerning the year in a diachronic order. The Rhemes of the text begin with "football association" and end with "football". All other Themes are concerned with football. The echo can be found through the whole text. The patterns of thematic progression of the whole text are as follows:

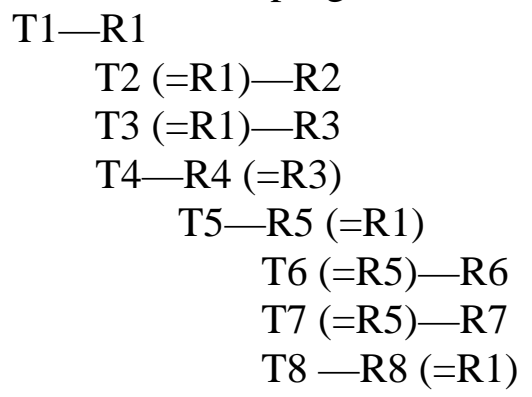

The major pattern adopted in this text is the Extending Theme Pattern ( 5 times, occupying $55.6 \%$ ). The next pattern used in this text is Continuous Theme Pattern (3 times, occupying 33.3\%). R1 and T2, T3 are hyponymy; R5 and T6, T7 are hyponymy; the topic here are concerning football. T1, T5 are co-reference, which is about the temporal development. From this thematic progression, it can be observed that from T1 to T4, it is closely related in one topic, concerning the development of football before 1870s; From T5 to T8 is another topic concerning the development of football after 1870s. From R5=R1 and R8=R1, the conclusion can be easily obtained that the whole passage is a coherent whole. Thus it is obvious that the whole text is about the development of the football game in the world. Through the analysis of its thematic progression pattern, it can be demonstrated that the whole text is coherent. 


\section{Summary}

In a word, the patterns of thematic progression play an important role in text analysis. Through the analysis of thematic progression and of sense relations within each sentence, the cohesion and coherence of the text is obvious and the development of the text is also transparent.

\section{References}

[1] Bloor, T and M. Bloor. The Functional Analysis of English: A Hallidayan Approach [M]. London: Edward Arnold, 1995.

[2] Danes, F. Papers in Functional Sentence Perspective [M]. Prague: Academia, 1974.

[3] Halliday, M.A.K an Introduction to Functional Grammar [M]. London: Edward Arnold, 1994.

[4] Thomson, G. Introducing Functional Grammar [M]. London: Edward Arnold, 1996.

[5] Hu Zhuanglin, Zhu Yongsheng \& Zhang Delu an Introduction to Functional Grammar [M]. Changsha: Hunan Education Press, 1989.

[6] Zhu Yongsheng, Yanshiqing Reflections on Systemic Functional Linguistics [M]. Shanghai: Shanghai Foreign Language Education Press, 2001. 